\title{
Study of serum copper and zinc levels in association with albumin and uric acid as antioxidant markers in type II diabetes mellitus
}

\author{
E. Manideep ${ }^{1}$, P. Aruna ${ }^{2, *}$, Amar Nagesh Kumar ${ }^{3}$ \\ ${ }^{1}$ MBBS Student, ${ }^{2,3}$ Assistant Professor, Dept. of Biochemistry, ${ }^{1,2}$ ACSR Government Medical College \& Hospital, \\ Nellore, Andhra Pradesh, ${ }^{3}$ Karpaga Vinayaga Institute of Medical Sciences, Madhurantagam, Tamil Nadu, India
}

*Corresponding Author:

Email: draruna77@gmail.com

\begin{abstract}
Introduction: Type II Diabetes mellitus (type II DM) is a chronic metabolic disorder characterised by oxidative stress. Free radicals play a pivotal role in the progression of diabetes and its complications. The role of trace elements in type II DM is always controversial. Antioxidants are very important in reducing the impact of oxidative stress. Hyperglycemia induces oxidative stress which in turn causes damage to copper binding proteins and lead to release of copper ions.

Aims and Objectives: The present study was designed to establish an association of trace elements serum copper and zinc with serum albumin and uric acid as antioxidants in type II DM.

Materials and Methods: Study includes 30 type II diabetic patients as cases and 30 normal individuals as controls. Fasting blood sugar (FBS) and Post prandial blood sugar (PPBS), serum copper, zinc, uric acid and albumin levels were measured in all the subjects. In our study serum copper levels were increased and zinc levels were decreased in cases when compared to controls. FBS and PPBS levels in our study showed positive correlation with serum copper levels. Serum uric acid levels in cases were increased in comparison to controls. Although there was decrease in albumin levels in this study, it was not statistically significant. However, we could not establish an association of trace elements copper and zinc with the antioxidants like uric acid and albumin in our study probably because of the small sample size.

Conclusion: Inclusion of trace elements like copper, zinc and antioxidants like uric acid, albumin in the panel of investigations for diabetes mellitus (D.M) may be useful in predicting the prognosis of type II DM and early detection of its complications.
\end{abstract}

Keywords: Antioxidants, Diabetes, Oxidative stress, Serum albumin, Serum copper, Serum zinc.

Received: $06^{\text {th }}$ November, 2017

\section{Introduction}

Diabetes mellitus (DM) is a group of metabolic disorders characterized by a chronic hyperglycemic condition resulting from defects in insulin secretion, insulin action or both. ${ }^{1}$ Type II diabetes is the commonest form of diabetes and associated with multiple metabolic derangements that result in the excessive production of reactive oxygen species and oxidative stress. To counteract the harmful effects of free radicals, antioxidant defense mechanism operates to detoxify or scavenge these free radicals. ${ }^{2}$

Abnormal copper metabolism is associated with human and experimental diabetes. ${ }^{3}$ The increase in $\mathrm{Cu}$ ion levels in patients with diabetes mellitus may be attributed to hyperglycaemia that may stimulate glycation and release of copper ions and this accelerates the oxidative stress, so that, advanced glycation end products are formed, ${ }^{3,4}$ that are involved in the pathogenesis of diabetic complications.
Accepted: $08^{\text {th }}$ November, 2017

Zinc ( $\mathrm{Zn}$ ) plays a functional act in nervous and immune systems, hormones activity, growth and development. $\mathrm{Zn}$ is an important micronutrient, which has a major role in synthesis, storage, secretion and function of insulin and its metabolism is altered in diabetes. ${ }^{5}$ $\mathrm{Zn}$ deficiency is correlated with insulin resistance. ${ }^{5-7}$

Free radical production is increased during diabetes. Serum albumin is a major antioxidant agent, and structural modification of albumin induced by glucose or free radicals impairs its antioxidant properties. $^{8}$ Uric acid plays the protective role during the formation of free radicals. ${ }^{9}$ An important observation was that uric acid may function as an antioxidant, which is of great importance in plasma. ${ }^{9}$ The present study was designed in order to estimate the alterations in the levels of the trace elements such as copper and zinc in type 2 diabetes mellitus patients in association with albumin and uric acid as antioxidant markers. 


\section{Materials and Methods}

The present study was carried out for a period of two months on diagnosed patients of type II diabetes mellitus attending General medicine department as out patient and impatients at ACSR Government Medical College and Hospital, Nellore. The study included 30 type II diabetes mellitus patients as cases and 30 normal individuals as controls. The study was approved by Institutional ethical committee of ACSR Government Medical College and Hospital, Nellore, Andhra Pradesh. All the participants were informed about the purpose of the study and written informed consent was obtained from them.

About $5 \mathrm{ml}$ venous blood was collected from all the study subjects under aseptic precautions. Blood was transferred into a plain tube and allowed to clot for 15 minutes. Then serum was separated by centrifugation and stored at $-20^{\circ} \mathrm{C}$ until further analysis. About $2 \mathrm{ml}$ of venous blood collected similarly for post prandial blood glucose analysis.

Inclusion criteria: Subjects should have been type II diabetic for at least one year duration without any complications.

Exclusion criteria: Patients on thyroid stimulating drugs, corticosteroids, lipid lowering drugs, oral contraceptives, aspirin, sulphonamides and those diabetic patients with a history of diabetic retinopathy, nephropathy, and neuropathy were excluded.

All the serum samples were analyzed for fasting and post prandial blood sugar, serum copper, serum zinc, serum uric acid and serum albumin. Serum FBS and PPBS was determined by the glucose oxidase and peroxidase (GOD POD) method using a commercially available kit in a semi auto analyser. Normal values of serum fasting blood sugar: $70-110 \mathrm{mg} / \mathrm{dl}$ and Post prandial blood sugar: $<140 \mathrm{mg} / \mathrm{dl}$. Estimation of serum copper and serum zinc was carried out by colorimetric method using the commercial kits available in the market. Normal reference values of serum copper in males - $80-140 \mu \mathrm{g} / \mathrm{dl}$; while in females it is: $80-155 \mu \mathrm{g} / \mathrm{dl}$. Normal range of serum zinc levels is - $60-120 \mu \mathrm{g} / \mathrm{dl}$. Estimation of serum uric acid by was carried out by UricasePOD method using commercially available kit for semi auto analyzer (Coral - Uric acid-MR LIQUIZONE). Normal range of uric acid in men is $3.4-7.0 \mathrm{mg} / \mathrm{dl}$ and in women is $2.4-5.7$ $\mathrm{mg} / \mathrm{dl}$. Estimation of serum albumin was done by using albumin kit (BCG-dye method). Normal range of serum albumin is $3.2-5.0 \mathrm{~g} / \mathrm{dl}$. The mean and standard deviation were calculated for all the biochemical parameters. The significance between the groups was determined using Student $\mathrm{t}-$ test for Equality of means. The pvalue of $<0.05$ was considered significant.

\section{Results}

The present study included 60 subjects. Among them 30 were type II diabetic individuals with a duration of more than one year and other 30 subjects were normal. In all the study subjects serum FBS, PPBS, copper, zinc, uric acid, albumin were estimated and the mean values compared and analyzed. In the present study the mean values of serum FBS in controls were $84.7 \pm 10.1 \mathrm{mg} / \mathrm{dl}$ and in diabetes patients were $147.5 \pm 15.6 \mathrm{mg} / \mathrm{dl}$. The results were statistically significant $(\mathrm{p}<0.0001)$ as shown in table 1 . In the present study the mean \pm SD of PPBS in controls $(n=30)$ and cases $(n=30)$ were $117.5 \pm 9.2$ and $236.1 \pm 36.4 \mathrm{mg} / \mathrm{dl}$ respectively. This increase was statistically significant $(\mathrm{p}<0.0001)$ as shown in table 1 . The mean value \pm SD of serum copper in controls $(\mathrm{n}=30)$ and type II diabetes cases $(\mathrm{n}=30)$ were $113.0 \pm 32.5 \mu \mathrm{g} / \mathrm{dl}$ and $189.7 \pm 56.4$ $\mu \mathrm{g} / \mathrm{dl}$ respectively. This increase was statistically significant $(p<0.0001)$ as shown in table 1 . The mean value and standard deviation of serum zinc in controls $(\mathrm{n}=30)$ and diabetes cases $(\mathrm{n}=30)$ were $99.6 \pm 24.1 \mu \mathrm{g} / \mathrm{dl}$ and $48.8 \pm 14.0 \mu \mathrm{g} / \mathrm{dl}$ respectively. This decrease was statistically significant $(p<0.0001)$ as shown in table 1 . The mean value and standard deviation of uric acid in controls $(n=30)$ and cases $(n=30)$ were $4.8 \pm 1.3 \mathrm{mg} / \mathrm{dl}$ and $12.3 \pm 8 \mathrm{mg} / \mathrm{dl}$ respectively. The increase in mean uric acid levels were statistically significant $(\mathrm{p}<0.0001)$ as shown in table 1 . The mean value and standard deviation of albumin in controls $(n=30)$ and cases $(n=50)$ were $5.35 \pm 1.7 \mathrm{~g} / \mathrm{dl}$ and $4.7 \pm 2.3 \mathrm{~g} / \mathrm{dl}$ respectively. There was decrease in the serum albumin levels between the two groups but the decrease was not statistically significant $(\mathrm{p}=0.2182)$ as shown in table 1.

Pearson correlation and regression analysis was done for all the parameters among diabetic patients. (Table No.2)A positive correlation was observed between serum fasting glucose levels and PPBS ( $r=0.79 ; p<0.05$, Fig. 2$)$. Similarly there was a positive correlation between FBS and serum copper. $(r=0.608 ; \mathrm{p}<0.05$.It clearly suggests that more the fasting glucose value in diabetic patients more the serum copper levels (Table 2). Other than serum copper and serum glucose, no other parameter show either positive or negative significant correlation among diabetic patients. 


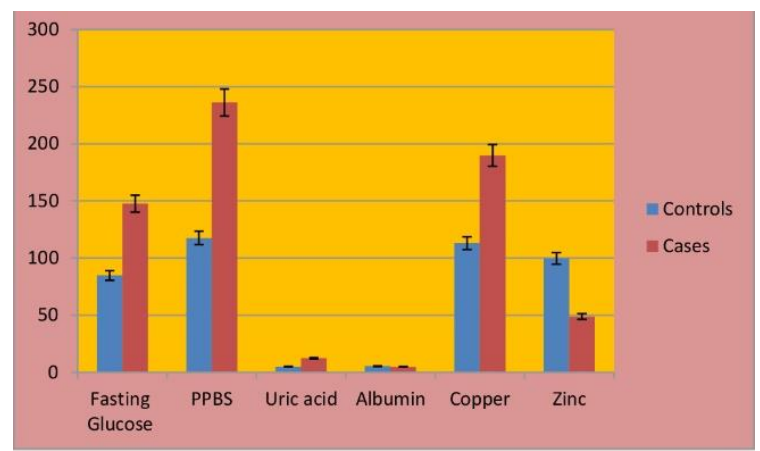

Fig. 1: Comparison of mean values of study variables in cases and controls

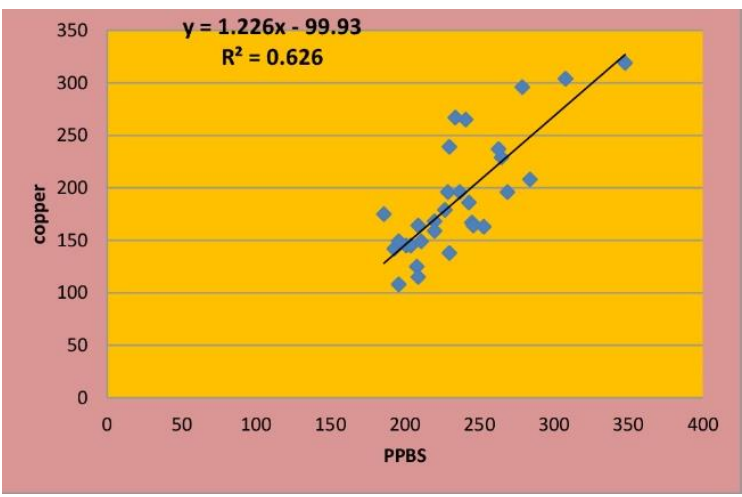

Fig. 2: Scatter diagram showing correlation between PPBS and S. Copper in cases

Table 1: Showing the mean \pm SD and $p$ value of study variables in controls and cases

\begin{tabular}{|l|l|l|l|}
\hline \multirow{2}{*}{} & \multicolumn{1}{|c|}{ Controls } & \multicolumn{1}{c|}{ Cases } & \multicolumn{1}{c|}{ P value } \\
\cline { 2 - 4 } & \multicolumn{1}{c|}{ Mean \pm SD } & \multicolumn{1}{c|}{ Mean \pm SD } & \\
\hline Fasting Glucose & $84.7 \pm 10.1$ & $147.5 \pm 15.6$ & 0.0001 \\
\hline PPBS & $117.5 \pm 9.2$ & $236.1 \pm 36.4$ & 0.0001 \\
\hline Uric acid & $4.8 \pm 1.3$ & $12.3 \pm 8.0$ & 0.0001 \\
\hline Albumin & $5.35 \pm 1.7$ & $4.7 \pm 2.3$ & 0.2182 \\
\hline Copper & $113.0 \pm 32.5$ & $189.7 \pm 56.4$ & 0.0001 \\
\hline Zinc & $99.6 \pm 24.1$ & $48.8 \pm 14.0$ & 0.0001 \\
\hline
\end{tabular}

Table 2: Correlation analysis of study variables among cases

\begin{tabular}{|l|l|l|l|l|l|l|}
\hline & $\begin{array}{l}\text { Fasting } \\
\text { Glucose }\end{array}$ & PPBS & $\begin{array}{c}\text { Uric } \\
\text { acid }\end{array}$ & Albumin & Copper & Zinc \\
\hline Fasting Glucose & 1 & $\mathbf{0 . 7 0 1}$ & -0.223 & -0.374 & $\mathbf{0 . 6 0 8}$ & 0.071 \\
\hline PPBS & 0.701 & 1 & -0.163 & -0.275 & 0.791 & -0.046 \\
\hline Uric acid & -0.223 & -0.163 & 1 & 0.423 & -0.145 & -0.128 \\
\hline Albumin & -0.374 & -0.275 & $\mathbf{0 . 4 2 3}$ & 1 & -0.337 & -0.253 \\
\hline Copper & 0.608 & $\mathbf{0 . 7 9 1}$ & -0.145 & -0.337 & 1 & 0.008 \\
\hline Zinc & 0.071 & -0.046 & -0.128 & -0.253 & 0.008 & 1 \\
\hline
\end{tabular}

\section{Discussion}

Diabetes Mellitus (DM) is a disorder characterized by persistent hyperglycemia due to insulin resistance. ${ }^{11}$ Oxidative stress is implicated in the patho physiology of diabetes mellitus and its chronic complications. ${ }^{12}$ It is well established that both, the deficiency and possible overload of mineral micronutrients have adverse health effects. ${ }^{13}$

The increase in copper levels in patients with type II DM might also be attributed to 
hyperglycaemia, which stimulates glycation and causes release of copper ions from copper binding sites of proteins. The release of copper ions into blood further accelerates the oxidative stress. ${ }^{14}$

In our present study the serum copper levels were elevated in cases when compared to controls ( $p$ value $<0.0001$ ). This increase in serum copper levels in cases was statistically significant in cases when compared to controls (Table 1). This was in accordance with the study done by Savu O et al, ${ }^{12}$ Devi TR et al, ${ }^{15}$ Puri M et al. $^{3}$ There was positive correlation between fasting glucose and copper $(r=0.6, p<0.01)$.

Zinc is essential for insulin synthesis and storage and its deficiency leads to diabetes associated complications ${ }^{16}$. Serum zinc levels were decreased in cases in our study when compared to controls ( $\mathrm{p}$ value $<0.0001$ ). This decrease was statistically significant in cases when compared to controls (Table 1). This was in accordance with the study done by Devi TR et al ${ }^{15}$ Puri Met al. ${ }^{3}$ However, Zargar A et $\mathrm{al}^{17}$ showed that zinc and Magnesium levels were not altered in their study.

Cooper et $\mathrm{al}^{13}$ have shown that the copper chelator trientine, given to diabetes induced rats, alleviated their heart failure, improved cardiomyocyte structure, and reversed elevations in left ventricular collagen and $\beta 1$ integrin without lowering blood glucose. They followed this up with studies in diabetic patients and showed that trientine therapy decreased left ventricular hypertrophy

Jayawardena $\mathrm{R}$ et $\mathrm{al}^{18}$ showed a significant reduction in systolic and diastolic blood pressures after Zinc supplementation. Zinc supplementation in patients with diabetes, a meta-analysis study, demonstrated that Zinc supplementation had beneficial effects on glycaemic control and promoted healthy lipid parameters.

Sun $\mathrm{Q}$ et $\mathrm{al}{ }^{19}$ in their study provided novel evidence that zinc intake might be associated with a lower risk of type 2 diabetes in U.S. women. The possible explanation of the observed hypozincemia in diabetes is hyperzincuria which occurs as a result of hyperglycaemia, disrupting the proper metabolism of trace elements. ${ }^{20}$

Uric acid is a major antioxidant of our body. ${ }^{9}$ In our present study serum uric acid levels were increased when compared to controls ( $p$ value $<0.0001)$. This increase in uric acid levels in cases was statistically significant when compared to cases (Table 1, Fig. 2). This was in accordance with the study done by Gawlik et al ${ }^{21}$ Matough FA et al. ${ }^{10}$
Total thiol pool contributes majority of antioxidant activity of the body. Major contribution to total thiol pool is from reduced glutathione (GSH) and free thiol (SH) group present on protein mainly on albumin..$^{22}$ In our study serum albumin levels among cases were decreased when compared to controls ( $p$ value $=0.2182$ ). This decrease in albumin levels in cases in comparison with the cases was not statistically significant (Table 1).

Savu $\mathrm{O}$ et $\mathrm{al}^{23}$ showed that concentrations of plasma albumin were significantly lower, and uric acid significantly higher, in diabetic patients when compared to controls. They showed that copper levels were also significantly increased in their study. Hisalkar $\mathrm{PJ}^{2}$ study showed a statistically decreased uric acid and albumin levels in diabetic patients in comparison with the controls. However Kiran BS et $\mathrm{al}^{11}$ showed a significant increase in uric acid and albumin.

Gawlik et $\mathrm{al}^{21}$ showed a significant correlation between uric acid concentration and plasma total antioxidant capacity both in diabetes patients and in the control group. Significant correlation between serum uric acid and albuminuria was also demonstrated in their study. Sarkar A et $\mathrm{al}^{22}$ found significant increase in levels of copper and fasting plasma glucose in type II diabetes mellitus patients. They showed a negative correlation of fasting plasma glucose with antioxidants like ceruloplasmin and total thiols in their study.

They further concluded that patients with type II diabetes had a decrease in the antioxidant properties of serum albumins. Moreover, a significant protection of albumin was found in patients with type II diabetes mellitus treated with metformin. ${ }^{22}$

Faure Patrice et $\mathrm{al}^{8}$ investigated the antioxidant property of serum albumin by determining albumin oxidation (albumin thiol groups) and the structural changes in albumin was assessed by tryptophan accessibility (fluorescence quenching by acrylamide). The decreased intrinsic fluorescence of albumin reflected the more difficult access to the two tryptophan residues; which in turn explained the changes in the conformational properties of the protein.

However, we could not establish an association of trace elements copper and zinc with the antioxidants like uric acid and albumin in our study probably because of the small sample size.

Matough FA et $\mathrm{al}^{10}$ in their study showed that some components of antioxidant defence such as glutathione reductase, uric acid, and GGT were increased in type 2 diabetes. 
Although increased, the whole system of antioxidant defence cannot compensate for an enhanced production of ROS in diabetes, this further resulted in oxidative stress. These data may indicate the use of future clinical trials of therapies to enhance the antioxidant defence. It is also important to conduct well designed randomized control trials in those with prediabetes to evaluate potential beneficial effects of copper chelation therapy and zinc supplementation in prevention of diabetes.

\section{Conclusion}

Hyperglycemia induces free radicals and impairs the endogenous antioxidant defense system in diabetes mellitus. In our present study serum copper and zinc levels were altered in type II DM. Serum uric acid levels were elevated in cases when compared to controls and serum albumin levels were decreased but this was not statistically significant. However, we could not establish an association of trace elements with the antioxidants in our study. Because of important role of zinc in type II DM, an adequate supply of this in the diet may be recommended. The study therefore suggests that the estimation of plasma antioxidants with other routine investigations may be useful in the prevention of diabetic complications.

\section{Acknowledgements}

This study was selected and approved as STS project by ICMR in the year 2016.

\section{References}

1. Ozougwu JC, Obimba KC, Belonwu CD, Unakalamba CB. The pathogenesis and pathophysiology of type 1 and type 2 diabetes mellitus. The journal of physiology and pathophysiology. 2013; 4(4):46-57.

2. Hisalkar PJ, Patne AB, Fawade MM. Assessment of plasma antioxidant levels in type 2 diabetes patients. Int J Biol Med Res. 2012;3(2):1796-800.

3. Puri M, Gujral U, Nayyar SB. Comparative study of serum zinc, magnesium and copper levels among patients of type 2 Diabetes mellitus with and without microangiopathic complications. Innovative Journal of Medical and Health Science. 2013;3(6):274-8.

4. Mosad A, Seif A, Yousef AA. Evaluation of some biochemical changes in diabetic patients. Clinica Chemica Acta. 2004;346:161-70.

5. Makhlough A, Makhlough M, Shokrzadeh M, Mohammadian M, Sedighi O, Faghihan M. Comparing the Levels of Trace Elements in Patients With Diabetic Nephropathy and Healthy Individuals. Nephrourol Mon. 2015;7(4):e28576.
6. Marreiro DN, Geloneze B, Tambascia MA, Lerario AC, Halpern A, Cozzolino SM. Effect of zinc supplementation on serum leptin levels and insulin resistance of obese women. Biol Trace Elem Res. 2006;112(2):109-18.

7. Kim J, Lee S. Effect of zinc supplementation on insulin resistance and metabolic risk factors in obese Korean women. Nutr Res Pract. 2012;6(3):221-5.

8. Patrice F, Wiernsperger N, Polge C, Favier A, Halimi S. Impairment of the Antioxidant Properties of Serum Albumin in Patients with Diabetes: Protective Effects of Metformin. Clinical Science. 2008; 114(3):251-6.

9. Kumar AN, Aruna P, Naidu JN, Kumar R, Srivastava AK. Review of concepts and controversies of uric acid as antioxidant and prooxidant. Archives Medical Review Journal. 2015;24(1):19-40.

10. Matough FA, Budin SB, Hamid ZA, Alwahaibi N, Sultan Qaboos JM. The Role of Oxidative Stress and Antioxidants in Diabetic Complications. Univ Med J. 2012;12(1):5-18.

11. Kiran SR, Lakshmi TM, Srikumar R, Reddy EP. Total Antioxidant Status and Oxidative Stress in Diabetes Mellitus and Metabolic Syndrome. Int. J. Pharm. Sci. Rev. Res., 2016;40(1):271-7.

12. Flores CR, Puga MP, Wrobel K, Garay Sevilla ME, Wrobel K. Trace elements status in diabetes mellitus type 2: Possible role of the interaction between molybdenum and copper in the progress of typical complications. Diabetes Res Clin Pract. 2011;91(3):333-41.

13. Cooper GJS, Young AA, Gamble GD, Occleshaw CJ, Dissanayake AM, Cowan BR, Brunton DH, Baker JR, Phillips AR, Frampton CM et al: A copper (II)-selective chelator ameliorates leftventricular hypertrophy in type 2 diabetic patients: a randomised placebo-controlled study. Diabetologia. 2009; 52(4):715-22.

14. Mohanty S, Bharatkumar PV, Murgod R, Raghavendra DS. Evaluation of Serum Copper, Magnesium and Glycated Haemoglobin in Type 2 Diabetes Mellitus. Asian J Pharm Clin Res. 2013;6(2):188-90.

15. Romola DT, Hijam D, Dubey A, Debnath S, Oinam P, Taruni Devi NG, Gyaneshwar Singh WG. Study of Serum Zinc and Copper Levels in Type 2 Diabetes Mellitus. Last accessed on October 10, 2016. http://www.academia.edu/download/45593598/34 .pdf.

16. Jyothirmayi B, Vasantha M. Study of Zinc and Glycated Hb Levels in Diabetic Complications. International Journal of Pharmaceutical and Clinical Research. 2015;7(5):360-3.

17. Zargar AH, Shah NA, Masoodi SR, Laway BA, Dar FA, Khan AR, et al. Copper, zinc, and magnesium levels in non-insulin dependent diabetes mellitus. Postgraduate Medical Journal. 1998;74(877):665-8.

18. Jayawardena $R$, Ranasinghe $P$, Galappatthy $P$, Malkanthi R, Constantine G, Katulanda P. Effects of zinc supplementation on diabetes mellitus: a systematic review and meta-analysis. Diabetol Metab Syndr. 2012;4(1):13.

19. Sun Q, Dam RM van, Willett WC, Hu FB. Prospective Study of Zinc Intake and Risk of 
Type 2 Diabetes in Women. Diabetes Care. 2009;32(4):629-34.

20. Olaniyan O, Awonuga MAM, Ajetunmobi AF, Adeleke IA, Fagbolade OJ, Olabiyi KO,

Oyekanmi BA, Osadolor HB. Serum copper and zinc levels in Nigerian type 2 diabetic patients. African Journal of Diabetes Medicine. 2012;20(2):36-8.

21. Gawlik K, Naskalski JW, Fedak D, PawlicaGosiewska D, Grudzie U, Dumnicka P, Ma, Ecki MT, Solnica B. Markers of Antioxidant Defense in Patients with Type 2 Diabetes. Oxidative Medicine and Cellular Longevity. 2016: e2352361. doi:10.1155/2016/2352361.

22. Sarkar A, Dash S, Barik BK, Muttigi MS, Kedage V, Shetty JK, Prakash M. Copper and Ceruloplasmin Levels in Relation to Total Thiols and GST in Type 2 Diabetes Mellitus Patients. Indian Journal of Clinical Biochemistry. 2010;25(1):74-6.

23. Savu O, Ionescu-Tirgoviste C, Atanasiu V, Gaman L, Papacocea R, Stoian I. Increase in Total Antioxidant Capacity of Plasma despite High Levels of Oxidative Stress in Uncomplicated Type 2 Diabetes Mellitus. Journal of International Medical Research. 2012;40(2):709-16. 